\title{
Buscando caminhos nos processos de formação/autoformação*
}

\section{Cleide Figueiredo Leitão}

SAPÉ - Serviços de Apoio à Pesquisa em Educação
Eu diria que os educadores são como as velhas árvores. Possuem uma fase, um nome, uma "estória" a ser contada. Habitam um mundo em que o que vale é a relação que os liga aos alunos, sendo que cada aluno é uma "entidade" sui generis, portador de um nome, também de uma "estória", sofrendo tristezas e alimentando esperanças. E a educação é algo pra acontecer neste espaço invisível e denso, que se estabelece a dois.

Rubem Alves, Espaço artesanal.

\section{Primeiro movimento: o lugar de onde emerge a experiência}

As questões e reflexões sobre processos de autoformação de educadores que compartilho neste texto foram sendo amadurecidas ao longo da experiência

* Artigo elaborado com base na dissertação de mestrado realizada sob orientação da professora Inês Barbosa de Oliveira e defendida no Programa de Pós-Graduação da Faculdade de Edu- com os Coletivos de Autoformação de educadores dinamizados pelo SAPÉ, ${ }^{1}$ ao longo de oito anos, de 1991 a 1998, com dois grupos de educadores e educadoras, um no estado de Pernambuco, outro no Rio de Janeiro.

A origem da instituição está ligada à pesquisa Confronto de Sistemas de Conhecimentos na Educação Popular. Inicialmente, essa pesquisa foi planejada para ser desenvolvida em quatro vertentes: alfabetização de adultos, educação política, formas alternativas de produção e ensaios de organização de populações de rua. Mas somente as duas primeiras

cação da Universidade do Estado do Rio de Janeiro, em dezembro de 2002. Apresentado no Grupo de Trabalho Educação de Pessoas Jovens e Adultas, durante a $26^{\mathrm{a}}$ Reunião Anual da ANPEd, realizada em Poços de Caldas, MG, de 5 a 8 de outubro de 2003.

1 SAPÉ - Serviços de Apoio à Pesquisa em Educação, organização não-governamental sediada no Rio de Janeiro, atua há quinze anos no campo da Educação de Jovens e Adultos (EJA) com ações voltadas para a formação de educadores e produção de materiais didáticos. 
foram realizadas, e o envolvimento intenso com a alfabetização de adultos foi importantíssimo na consolidação de um eixo do trabalho, denominado Formação/Autoformação de Educadores. Para o SAPÉ, isto significou a delimitação de um campo de trabalho específico na educação de jovens e adultos.

Com o término desta pesquisa, mapeamos algumas experiências no campo da alfabetização de jovens e adultos nos estados de Pernambuco e Rio de Janeiro, para confrontar e discutir os seus resultados, ao mesmo tempo em que intermediávamos as relações entre essas experiências, com o intuito de criar um espaço de confronto e debate em torno de questões comuns.

Passamos a nos reunir uma vez por ano com os educadores de Pernambuco e, com uma periodicidade maior, no Rio de Janeiro. Eram realizados seminários - forma escolhida para juntos debatermos e aprofundarmos um tema selecionado - que incluíam reuniões preparatórias para a escolha da temática, circulação de textos e uma organização gerencial da qual todos participavam. Aos poucos começamos a amadurecer a idéia da constituição de um coletivo, à medida que constatávamos um comprometimento das pessoas envolvidas com esse espaço, movidas, de um lado, pelo seu desejo e pela livre adesão e, por outro, pelo compromisso de cada um de tomar em suas mãos a tarefa de sua formação, a compartilhando, confrontando e enriquecendo com os demais.

Os Coletivos de Autoformação se constituíram então em espaços de mediação entre as práticas e a necessidade de refletir e teorizar sobre a ação, sendo este seu maior sentido e significado. Ofereciam, também, oportunidades de experimentação e investigação de metodologias de autoformação e confirmavam a importância do cotidiano e da experiência, na criação e socialização de saberes e conhecimentos pelos próprios educadores.

\section{Segundo movimento: questões sobre formação}

A palavra formação, devido a algumas práticas que nela são desenvolvidas, nos remete à idéia de dar forma, moldar, como se os outros - educadores, pro- fessores - fossem uma massa amorfa que só saísse desse estado a partir das informações, conteúdos e teorias que orientam as propostas formadoras. Esse entendimento da formação como algo externo ao sujeito e localizado somente no conhecimento ou naquele que o transmite, por mais que estes sejam inovadores e atuais, é limitado e simplista. Mera ilusão de um poder que não quer ver a capacidade do outro de se apropriar, fazer próprio, reapropriar-se, na busca de um sentido que, em vez de superpor saberes, favoreça que os saberes de cada um se alarguem a partir de outros entendimentos e apropriações.

Muitas vezes ouvimos que o fracasso das experiências educativas (escolares ou não escolares) se deve ao despreparo e, principalmente, à má formação dos educadores. Além da redução do problema, bem mais complexo, no que diz respeito à formação e às condições necessárias a um bom desempenho educacional de grandes contingentes, como é o caso da população atendida pelas escolas públicas, esse lugar comum de atribuir a culpa aos professores volta-se como um bumerangue para as instituições responsáveis pela formação; e, ao atingi-las como co-responsáveis pelos problemas do desempenho docente e, por consequiência, discente, desnuda a responsabilidade e a "contribuição" de cada um dos envolvidos no processo.

No XI ENDIPE, ${ }^{2}$ entre os muitos contatos que tive oportunidade de fazer, conheci brevemente uma professora universitária que vem, já há algum tempo, pesquisando a formação de professores. Numa conversa rápida, ela dizia que não sabia o que estava acontecendo com a formação, pois esta não formava, não mudava a prática dos professores. Citava como exemplo um município do estado do Rio de Janeiro que tem investido de maneira diferencial em melhores condições de trabalho, valorização e preparação de seus docentes. Para ela, esta era a grande questão: por que a formação (supus que se referia à formação continuada) não modificava as práticas dos professores.

2 XI Encontro Nacional de Didática e Prática de Ensino, ocorrido em Goiânia de 26 a 29 de maio de 2002. 
Esse rápido encontro nos fez pensar sobre o que entendíamos por mudar as práticas dos professores. Na ocasião não tivemos tempo para aprofundar, mas é uma mudança externa que interfere no que é produzido, apontando outros caminhos? Ou uma mudança que tenta apreender, no que é feito, possibilidades de multiplicação de sentidos e busca de alternativas? São os dois movimentos que interagem, provocando deslocamentos no fazer pedagógico?

Mas o que mais me chamou a atenção foi a intenção daquela professora de, com sua pesquisa, achar a resposta e nos dizer. Fiquei pensando se ela acreditava mesmo que essa é uma resposta que se descobre sozinha, ou melhor, se uma pesquisa, por mais séria e bem-intencionada que seja, poderá dar conta de trazer as soluções para as questões complexas da formação. Pois já sabemos que uma hipótese ou uma descoberta não é jamais uma aquisição total do saber, mas sempre um fragmento do saber que impõe uma reorganização do saber anterior. Sem dúvida, seu trabalho, pela seriedade com que dele falava, trará mais uma compreensão sobre o tema, e talvez pistas importantes, que se somarão a outras pesquisas, a outras práticas, a outros processos de formação.

Esse pequeno relato é só para ilustrar parte do que é mais recorrente, intrigante e desafiante nessa questão: a consideração de que a formação necessária é aquela que se fundamenta nas mais "altas teorias", em conteúdos atualizados, em volume de conhecimentos adquiridos nos livros, e que só a partir desse percurso se chega à ação. Em contrapartida, é a recorrência das propostas feitas, em sua maioria, como experiências atualizadas, renovadoras, mas sempre de fora para dentro, que não se interrogam a respeito das múltiplas redes presentes na formação dos sujeitos e de como elas interagem continuamente, constituindo aquilo que somos e o que fazemos.

Apesar de todos os avanços em torno das concepções de educação - apoiados, sobretudo, no desenvolvimento das ciências humanas -, o que observamos é que nem sempre essas referências trazem modificações substanciais às práticas, nem garantem uma relação afetiva, um melhor desempenho no apren- dizado ou uma prática mais democrática, se os professores não estiverem sensibilizados e sentirem necessidade de participar dessa mudança. Ou seja, acredito que não é possível mudar sem a participação dos sujeitos - professores e alunos - que fazem a educação acontecer, sem nos interrogarmos profundamente sobre as formas pelas quais aprendemos e sem novas ressignificações de cada sujeito a partir do que é vivido e elaborado coletivamente.

Quando mudamos o modo de perceber e deslocamos a compreensão para o que ocorre e como ocorrem as práticas educativas, para as relações entre os principais envolvidos, para o que produzem de sentidos e significados, para as formas de produção, reprodução, criação e recriação dessas práticas, para o que o processo produz - apesar de todas as adversidades, todas as faltas e ausências, tudo o que ainda há para conquistar, seja em termos de condições para o desempenho da função, seja no necessário investimento em processos de formação/autoformação -, nos surpreendemos com a criatividade, as alternativas e as riquezas que, junto às ausências, estão presentes no cotidiano educativo.

Ora, se são os professores aqueles que conduzem o cotidiano da educação, apesar de todas as condições desfavoráveis que os cercam e das insuficiências em sua formação, é preciso acreditar que eles podem contribuir e participar na formulação e implantação das políticas de formação revelando o que sabem, o que desejam, o que querem, o que não querem, o que necessitam, contribuindo com o que têm a dizer, com o que fazem e como pensam e representam o que fazem.

Quero levantar algumas questões. O que empolga mesmo na discussão é a nossa necessidade, a nossa prática. É assim também com os professores com os quais lidamos: pedimos que eles relatem as suas experiências e as coisas mudam. (Simão, SME/EJA de Olinda)

Simão e Beto me perguntaram por que a graça de Benedito (mamulengo) era lascar o pau na nêga, tive que fazer uma autocrítica. Estamos acostumados a fazer 
mamulengo assim e o público acha a maior graça, terminamos por reproduzir. A pergunta deles foi um soco, porque participo do grupo de mulheres, levanto bandeira contra o racismo, contra o machismo, e na hora que estou com o instrumento de trabalho nas mãos reproduzo aquilo que critico. (Mabel, SME/EJA de Caruaru)

Os processos de formação estão relacionados ao que saber, por que saber e aos modos de saber na relação entre as pessoas. Se entendemos a relação com os saberes constituída também de afeto, solidariedade, curiosidade, insatisfação, provisoriedade - portanto, mais próxima da vida em seu movimento ininterrupto e dinâmico -, esse entendimento traz em seu interior incertezas, inseguranças e necessidade de mudanças, e com elas perdem-se algumas certezas, descobrem-se outras, sobre as quais também não temos garantias. Como às vezes também somos cegos a respeito de nossas ignorâncias e preferimos nos manter naquilo que parece mais seguro, deixamos de nos aventurar em busca de outras possibilidades favorecidas no encontro com os outros e perdemos por não aprendermos a buscar juntos.

Uma das questões centrais nessa discussão está na necessidade de se considerar as expressões das culturas locais, o singular, o específico, os saberes que cotidianamente são produzidos nas práticas educativas por aqueles que as fazem; práticas que são tecidas, destecidas, alinhavadas, no cotidiano, no diaa-dia, em um movimento prática-teoria-prática, para que, como diz Nóvoa (1995, p. 36), "os professores se apropriem dos saberes de que são portadores e os trabalhem do ponto de vista teórico e conceptual". Pois, do mesmo modo que a prática pode enriquecerse com a produção teórica e metodológica que a informa, as práticas, em sua riqueza e diversidade, também podem produzir teorias e metodologias em constante movimento.

As propostas de formação, além de oferecerem os já conhecidos cursos, palestras, seminários, oficinas, aulas de atualização, devem incluir também as necessárias condições que fomentem formas de organização dos próprios professores em cada unidade educativa, em um processo de autoformação partilhada, possibilitando a reflexão sobre as suas práticas, o aprofundamento de questões a elas pertinentes, espaços de trocas e convivências, o desenvolvimento de outras linguagens de expressão, o exercício da crítica e da criatividade e o aprofundamento das relações entre prática/teoria/prática. Enfim, espaços que favoreçam um exercício autônomo e sistemático das relações entre os seus fazeres, saberes, poderes.

Embora essas questões estejam relacionadas à formação de qualquer educador e educadora, no caso específico da educação de jovens e adultos constatamos também que, na maioria das vezes, o movimento da formação dos professores de jovens e adultos ainda se dá a partir das inquietações que os mesmos têm com suas práticas, das questões que delas emergem e do como procuram respondê-las, constituindo-se em um caminho de formação continuada muitas vezes percorrido solitariamente e de forma insuficiente para o atendimento das necessidades que se avolumam e que podem ser resumidas em: valorização da profissão; recursos definidos para esse fim; conhecimento de quem são os alunos jovens e adultos; criação de uma escola própria para o aluno jovem, adulto e trabalhador; tempo e espaço apropriados para a formação etc.

O campo da educação de jovens e adultos está repleto de desafios. Um deles é a contradição entre as leis que regem a área - a Constituição Federal, a Lei de Diretrizes e Bases da Educação Nacional, o parecer relativo à educação de jovens e adultos do Conselho Nacional de Educação, que apresentam avanços e garantem direitos -, e as políticas governamentais de caráter compensatório, que atribuem à educação de jovens e adultos um papel menor. Outro desafio é a relação entre o tempo necessário para uma formação de qualidade e a aceleração dos processos, tanto os de formação dos professores como os de aprendizagem dos alunos. No caso destes, principalmente pela pressão do mundo do trabalho. Mas o maior desafio é tentar responder a essas determinações na perspectiva de uma educação emancipatória, com o devido respeito que alunos e professores merecem. 


\section{Terceiro movimento: os sujeitos e os lugares da experiência}

O primeiro movimento que fizemos em direção a outros grupos que atuavam como nós na educação de jovens e adultos foi motivado tanto pelo desejo de compartilhar, trocar, debater e confrontar, ações que só são possíveis no coletivo, quanto por um sonho acalentado ao constatarmos a necessidade de investimento na formação, de imaginar outras possibilidades para esse processo, no qual pudéssemos, a partir dos diferentes lugares, pertencimentos e (hoje posso dizer) redes de significações, ampliar as relações entre o que somos, sentimos, pensamos e fazemos. Fortalecendo a prática pedagógica de cada experiência, como também aprofundando aquela que juntos tecíamos.

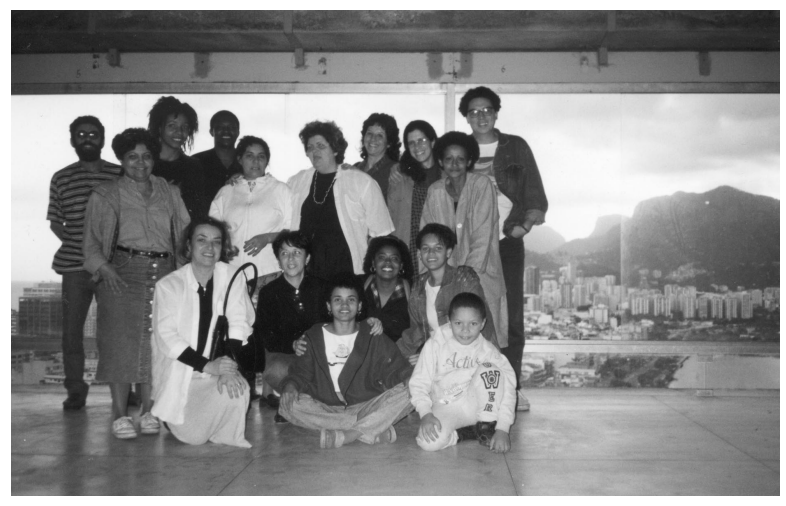

Figura 1 - VII Seminário do RJ, 1996. Coletivo de educadores. Fonte: Arquivo do SAPÉ.

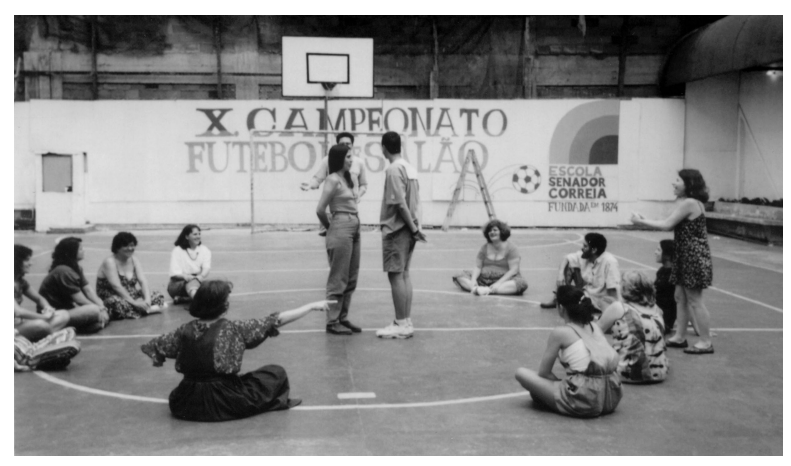

Figura 2 - VI Seminário do RJ, 1996. O lúdico na alfabetização de jovens e adultos. Fonte: Arquivo do SAPÉ.

E o que impulsionou o movimento foi imaginar outras possibilidades para o encontro, diferenciado nos estados de Pernambuco e do Rio de Janeiro, por- que cada local, cada cidade com suas paisagens, sua gente, aromas, sons, formas e cores, nos percorreu de forma diferenciada, como também nós as percorremos, sem esquecer que cada local também contém, em pequena escala, o mundo.

Rememorando os sujeitos e os lugares da experiência, percebo o quanto esse espaço de formação foi fundamental para cada um de seus participantes, no sentido de possibilitar outro entendimento e outra prática a respeito das questões colocadas anteriormente.

O meu desejo neste espaço é o de poder estar em contato com pessoas diferentes, que fazem um trabalho diferente, consciente de que aqui ninguém é perfeito. Mas sabendo que é fundamental aprender a lidar com toda essa diferença. (Sonia - Rio de Janeiro)

Eu estava ali, no espaço do Coletivo, porque queria, ninguém me mandava, ou não tinha que representar necessariamente a instituição em que trabalhava. Só o fato de poder estar ali pelo meu desejo, minha vontade, minha liberdade de escolha, era fundamental. (Angela - Pernambuco)

Entre os muitos exercícios educativos que realizamos na experiência dos Coletivos, dois, especialmente, foram fundamentais na consolidação dessa prática: o de construção coletiva de saberes/conhecimentos e o de vivência de relações mais democráticas, nas quais a contribuição de cada um era convocada e valorizada como um fator de enriquecimento do conjunto. Isso se expressava na divisão de responsabilidades na gerência dos seminários, forma escolhida para aprofundarmos as questões oriundas das práticas; na postura assumida de nos colocarmos nessa relação como parceiros dessa aventura pedagógica; e na convocação de educadores com as mais diferenciadas inserções: coordenadores da Educação de Jovens e Adultos, professores, educadores populares, diretores de escola e técnicos da EJA, vinculados a experiências governamentais e não-governamentais.

O grupo do Rio de Janeiro reunia muitos educadores leigos ligados à alfabetização de jovens e adultos 
das mais diferentes associações da sociedade civil: vinculadas às igrejas católica e protestante; escolas particulares; associações de moradores; centros comunitários; projetos com trabalhadores da construção civil etc. Experiências de frágil ou nenhuma institucionalidade, algumas se caracterizando por um trabalho voluntário, movidas apenas pelo intuito de participar e contribuir.

Esses alfabetizadores, em sua maioria, tinham aprendido o ofício fazendo, e traziam muitas dúvidas e questões sobre sua atuação. Por não terem tido preparo mais específico, em alguns momentos essa condição se refletia em sua auto-estima e na dificuldade de entendimento de alguns termos e linguagens próprias do campo da educação. No entanto, no levantamento de questões referentes à formação do educador, percebemos o quanto elas tinham de comum, independentemente de os educadores terem ou não formação inicial ou específica. Era convergente a sensação de despreparo para a prática alfabetizadora com adultos, mesmo entre aqueles educadores que tinham o curso normal ou curso universitário. De um lado, tínhamos o fato de a formação inicial ser insuficiente na preparação do professor para o trabalho com jovens e adultos; de outro, nos perguntávamos como investir na formação do enorme contingente de educadores leigos no país. A fala de Jussara, participante do Coletivo do Rio de Janeiro, alfabetizadora leiga da Vila Cruzeiro, traduz essa inquietação:

Fiquei pensando muito em relação à formação de professores leigos e habilitados, acho que o que fica valendo é a experiência adquirida no dia-a-dia e a capacidade de querer desenvolver o trabalho. Até há pouco tempo, eu tinha esse medo. Me sentia incapaz [...].

Esse sentimento de incapacidade, de medo, acometia não somente Jussara, mas tantos outros que não tinham inicialmente nem experiência nem conhecimento sistematizado nesse campo de atuação. A questão, portanto, estava na ausência de uma política de formação específica para o trabalho com jovens e adultos e, principalmente, de um processo de forma- ção/autoformação permanente, para aprimorar a prática e relacioná-la a outras contribuições, inclusive as teóricas, as já existentes, e à produção de pequenas teorias resultantes desse movimento de reflexão sobre a prática, exercitando assim um pensamento mais autônomo, crítico e criativo em relação aos nossos fazeres, saberes e poderes. Tanto o educador leigo quanto o professor formado precisam aperfeiçoar o seu ofício, os seus fazeres, reconhecendo que uma das nossas riquezas está na própria condição humana de experiência inacabada, o que nos possibilita aprender permanentemente.

No Coletivo de Pernambuco os educadores eram, em sua maioria, oriundos de experiências governamentais ligadas a programas de educação de jovens e adultos das secretarias municipais e estaduais de educação. Havia também professores de escolas estaduais e alguns educadores de organizações não-governamentais.

Esse Coletivo reunia educadores de várias regiões do estado, com predominância de educadores vinculados a experiências governamentais de maior porte e com as mais variadas inserções: coordenadores da educação de jovens e adultos, técnicos de ensino, educadores populares, professores do primeiro e segundo segmentos do ensino fundamental de jovens e adultos etc. Essas características permitiam traçar um painel variado das questões com as quais os educadores se defrontavam em seus diferentes locais de trabalho e em suas diferentes inserções.

Acho que temos muitas perguntas, muitas dúvidas sobre o que fazemos que ainda não foram ditas, mas podemos chegar lá, e acredito nisso pela maneira como vivemos essa experiência de pensar juntos, com essas diferenças todas. É difícil, mas é um processo, e a confiança e a vontade de melhorar vão nos levar a uma abertura, de nos expor naquilo que temos de bonito e naquilo que temos de feio. (Rute, II Seminário de PE, 1992)

O tema da formação de educadores foi recorrente nesse grupo; a cada encontro ele era acrescido com os elementos trazidos por cada experiência, incorporan- 
do as preocupações mais atuais. As diferenças entre as experiências governamentais bem mais complexas no desenvolvimento de seu trabalho pedagógico, em contraste com uma certa fluidez e autonomia presentes no trabalho das organizações não-governamentais contribuíram enormemente no enriquecimento das discussões, ao mesmo tempo em que possibilitou que identificássemos pontos em comum, tais como: o incentivo à criatividade e à autonomia do educador; o aprofundamento da relação prática/teoria/prática; a consideração da vontade pessoal e coletiva como elemento que impulsiona o processo de formação; a necessidade de processos de formação/autoformação que possibilitem a circulação do que é vivenciado, produzido, criticado pelos atores do processo; a adequação de critérios, métodos, técnicas e estratégias segundo as indicações do processo; e a produção e difusão de material de apoio facilitando a socialização de conhecimentos, experiências etc.

Entre os educadores com formação específica que participavam dos Coletivos, tanto no Rio de Janeiro quanto em Pernambuco, não temos notícia de nenhum que tivesse feito em sua formação inicial, no curso normal ou em pedagogia, alguma disciplina, habilitação ou especialização voltada para a EJA. A história de formação recorrente entre esses educadores era a de um aprendizado concomitante com a prática desenvolvida, que se caracterizava por ações de formação continuada promovidas por instituições como secretarias de educação e organizações nãogovernamentais. Concretamente, o que provocava uma mudança nas formas de educar, um jeito próprio de fazer, era a provocação dos desafios e, podemos dizer, uma "relação amorosa" e comprometida com esse campo de trabalho.

No decorrer dessa prática de autoformação, percebemos que o desejo de continuidade das discussões nos dois grupos expressava uma adesão ao processo iniciado. Simultaneamente, constatávamos que era preciso tempo para aprofundarmos questões relacionadas à prática/teoria/prática; aos processos de formação e autoformação (continuada, permanente); ao material didático para jovens e adultos: o que e como ensinar; à cultura dos alunos e ao reconhecimento de seus saberes; às linguagens expressivas na prática educativa; à autonomia do professor, entre tantas outras. Mas, mesmo nos dando mais tempo, sabíamos que as respostas que poderíamos dar teriam sempre um caráter provisório, intimamente relacionado às condições de nossas práticas, exigindo assim uma reflexão permanente.

\section{Quarto movimento: explicitando as diferenças e buscando os entre-lugares da formação}

A diversidade presente nos Coletivos, seja pela singularidade das histórias de vida de cada um, seja pelas diferentes inserções no campo profissional, nos interrogava incessantemente a respeito de como tratávamos a diversidade também presente nos espaços, de atuação: sala de aula, grupo de professores etc., e de como poderíamos nos enriquecer nessa dinâmica que, ao incorporar o outro, nos desaloja, nos desestabiliza, mas também nos movimenta num processo de alargamento de nossas fronteiras. Numa sociedade culturalmente diversificada como a nossa, como não incorporar a diversidade no entendimento do que somos e do que podemos fazer juntos?

Homi K. Bhabha (2001) traz uma importante contribuição quando diz: "o que é teoricamente inovador e politicamente crucial é a necessidade de passar além das narrativas de subjetividades originárias e iniciais e de focalizar aqueles momentos ou processos que são produzidos na articulação das diferenças culturais" (p. 20). Pois aí reside o desafio de muitas práticas e processos sociais e culturais, sobretudo os que são vinculados à formação e à prática educativa, entendendo-as enquanto lugares que favorecem encontros e a produção que pode ser feita a partir deles.

A noção de entre-lugares (Bhabha, 2001) em muito nos ajuda a entender a necessidade de deslocamento da lógica binária, isto ou aquilo, governamental ou não-governamental, instituídos e instituintes, para uma possibilidade de refletir e recriar a prática educativa no interstício entre esses lugares.

$\mathrm{O}$ respeito às diferenças não pode ser pensado 
sem que se considere que a questão da igualdade está relacionada às mais variadas formas de manifestação e reivindicação. Como bem nos aponta Santos (1999), é necessário aprofundar as complexas relações entre identidade e igualdade, desigualdade e diferença para se buscar uma nova articulação entre políticas de igualdade e políticas de identidade que considere que "temos o direito de ser iguais sempre que a diferença nos inferioriza assim como temos o direito de ser diferentes sempre que a igualdade nos descaracteriza" (p. 45).

Nesse sentido, os espaços educativos devem favorecer a vivência e o aprendizado da diversidade, $o$ convívio com as diferenças, as práticas coletivas, solidárias e fraternas, possibilitando o exercício da reflexão, da discussão, de outra qualidade de ação, mas também da escuta atenta, do gesto que se faz afetuoso e solidário, da atenção e do cuidado com todos e todas. A esse respeito, vale a pena ouvir/ler Florine, educadora integrante do Coletivo do Rio de Janeiro. Diz ela:

Havia uma organização conseguida a duras penas, porque tínhamos uma certa dificuldade para nos organizarmos no meio daquela diversidade. Era meio caótico, se formos parar pra pensar. Junta um povo da Escola Senador Correia com outro lá da Vila Cruzeiro, com outro que atua na Rocinha... E um é professor, o outro não é, outro está lá por causa da Igreja... Isso tornava tudo muito difícil, eram várias linguagens diferentes, expectativas diferentes e realidades diferentes. Mas também era isso que tornava tudo muito fascinante... Se nos propomos a trabalhar nesse universo tão amplo e tão diversificado, não podia ser uma coisa homogênea. Pelo contrário, era de uma heterogeneidade total. E a mim agrada muito mais assim, pois isso está mais próximo da vida do que tudo que é muito arrumado, muito certinho...

Na vida não é tudo arrumado, certinho o tempo todo. É verdade que você tenta se arrumar, os horários etc. Mas tem vezes que fica tudo complicado, do tipo não ter tempo de almoçar e comer um sanduíche na rua, e por aí vai. Sabe, lá tinha um espaço para o inesperado, para coisas malucas, para o que também não dava certo. Uma coisa mais verdadeira, mais parecida com a vida.
Compõem a complexidade dos processos de formação a convivência com as diferenças, as relações entre variados espaços educativos, as questões que emergem das práticas e a possibilidade de exercitar uma outra qualidade de relações, todas matérias-primas desse processo e alimentadoras da busca, da possibilidade do encontro, pois é essa busca de respostas, mesmo provisórias, que nos faz avançar.

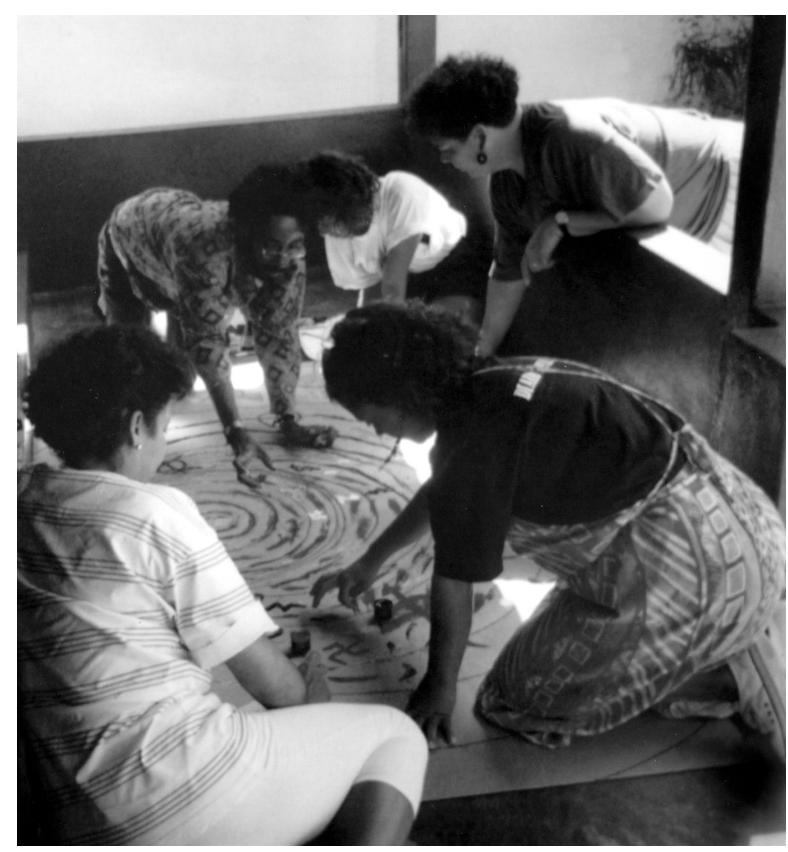

Figura 3 - IV Seminário de PE, 1994. A formação do educador, o contexto neoliberal e as linguagens expressivas. Fonte: Arquivo do SAPÉ.

Se o que dá sentido à busca é a possibilidade de encontro, e entendendo a educação como um espaço que permite o encontro, a convivência entre diferentes pessoas, essas questões precisam permear esse espaço para que, discutidas coletivamente, possam de fato contribuir para o alargamento do que somos e do que sabemos, diminuindo nossa ignorância a respeito daquilo que desconhecemos e nos enriquecendo nesse encontro com os outros, outros que também somos nós.

A vontade política de mudanças no cenário da educação e, especificamente, no da educação de jovens e adultos, que imprimam mais qualidade às rela- 
ções, precisam da vontade, do desejo, da adesão por parte daqueles que tecem em seu cotidiano esse fazer. Mas sabemos também que, além dessa livre adesão, é fundamental e necessário avançar na luta, às vezes solitária no âmbito do individual, às vezes compartilhada quando no coletivo, com a forma como aprendemos, como fomos formados considerando os saberes dicotômicos, fragmentados, hierarquizados. O desafio consiste em se fazer fazendo, nos modificarmos no próprio percurso, refletindo sobre essa trajetória coletivamente, considerando que é a partir do desejo e dessa luta que podemos, comprometidamente, refazer os caminhos, descobrir as alternativas que já se anunciam e criar outras possibilidades que precisam de tempo para amadurecer. Essa perspectiva contraria as propostas que condicionam a formação a um tempo aligeirado, insuficiente para que de fato se produzam mudanças substanciais.

Os espaços da formação são múltiplos, como o são as redes de saberes existentes no nosso vasto e complexo mundo, saberes que circulam entre as pessoas, interagindo e sendo apropriados segundo os usos e os significados a eles atribuídos por cada um. Esses saberes compõem uma tessitura indissociável, que se expressa no que somos e no que fazemos, perpassando tanto nossas identidades como as práticas com as quais estamos envolvidos. E a formação, inesgotável, incompleta, inacabada, vai dando-se a partir das múltiplas relações entre as pessoas envolvidas, entre os seus saberes, valores, desejos, sentimentos, entre o que é vivenciado, modificado, apropriado, recriado, criado. Confrontando e ampliando as redes de saberes já existentes.

Não se trata de uma versão romântica ou mesmo ingênua considerar a possibilidade de ampliação que esses saberes oferecem às práticas pedagógicas. O que está em questão é o reconhecimento de que somos formados por diferentes redes de saberes, e a possibilidade de ampliação que essas redes nos oferecem não diz respeito só aos saberes com os quais nos identificamos ou elegemos como fundamentais, pois isso implica uma seleção que exclui o que está presente, mesmo que não queiramos admitir, mas está também na consideração de que os saberes conservadores, autoritários, ingênuos, preconceituosos, se expressam em nosso fazer, nos provocando, nos confrontando, nos indagando, exigindo mudanças.

Incorporar no processo formativo os próprios impasses e contradições das práticas educativas é profundamente desestabilizador, mas nos permite criar um espaço de confronto, pois nem sempre o que o outro é, e revela, é aquilo que nos agrada ou nos enriquece, mas pode sempre nos provocar, seja pela identificação, seja pela diferenciação. E as provocações nos movimentam em outras direções que se definem como possibilidades à medida que são identificadas, discutidas, confrontadas, compartilhadas. Esse processo amadurece a escolha. $\mathrm{O}$ confronto, nessa perspectiva, é inevitável e saudável, pois é parte inerente desse processo. E, quando explicitado, favorece uma releitura dos conhecimentos/saberes em jogo e dos valores em que eles se apóiam.

A possibilidade de ampliação das fronteiras, de alargamento do que somos e fazemos, se faz tanto no reconhecimento e na identificação com os iguais quanto no fortalecimento com o diferente, pois são eles os que mais nos interrogam, que provocam as mudanças. Além disso, há a luta com o inimigo que está dentro de nós, em um processo constante de autocrítica de nossos próprios atos. Essa convivência, que nem sempre é harmônica, nos fortalece, revigorando o exercício democrático cotidiano, necessário para que possamos exercer melhor nossas escolhas como cidadãos, como aqueles que produzem a cidade.

Entendendo a formação como uma intrincada rede de relações que acontece em múltiplos espaços/ tempos, percebemos o quanto ela é complexa, intrigante e desafiadora, exigindo um mergulho tanto na rede de subjetividades que nos constitui, como lembra Santos (2000), como nas esferas das práticas de formação que se articulam e se inter-relacionam: a prática acadêmica, a prática pedagógica cotidiana, a prática política coletiva, a ação governamental traduzida nas leis e diretrizes, e as pesquisas em educação, como bem indica Nilda Alves (1998).

Boaventura de Sousa Santos (2000) traz impor- 
tante contribuição teórica na compreensão desses diferentes espaços/tempos da educação, ao distinguir, entre muitos, seis espaços estruturais que representam as relações sociais nas sociedades capitalistas contemporâneas. São eles: o espaço doméstico, o espaço da produção, o espaço do mercado, o espaço da comunidade, o espaço da cidadania e o espaço mundial. Cada um deles é marcado por seis dimensões, que são: a unidade de prática social, as instituições, a dinâmica de desenvolvimento, as formas de poder, as formas de direito e as formas epistemológicas.

As relações entre as dimensões e os espaços estruturais são relativamente autônomas uma vez que, na prática, eles se inter-relacionam, se intercomunicam, se interpenetram das mais variadas formas. Mas essa relativa separação nos ajuda a perceber que cada espaço é uma comunidade de saber, com formas próprias de ser e de se comunicar e que precisamos considerar cada uma delas. Pois, assim como podemos identificar, nesses espaços, processos educacional, familiar, relacionado ao trabalho, econômico, da cidadania e da solidariedade, político e mundial, a educação de cunho acadêmico também é influenciada pelos conceitos e valores educacionais oriundos desses diferentes espaços.

A consideração dessa amplitude, das inúmeras relações possíveis na educação e nos processos de formação, se contrapõe à idéia de um só caminho, de um pensamento único, demonstrando sua inconsistência, apesar de ainda ser preponderante. E nos exige tecer esses diferentes fios, inclusive os que ainda são desconhecidos, mas que em sua invisibilidade colorem a vida com os sonhos e a utopia de possibilidades de mudanças; ao mesmo tempo em que exige aprender coletivamente a refazermos o tempo de aprender, de descobrir, de produzir, quem sabe, um mundo tão possível quanto necessário.

Ao ouvir/ler o relato de Maria Luiza, rememorando sua trajetória profissional, podemos perceber que, se na sua formação acadêmica havia uma ausência de articulação entre os conhecimentos aprendidos e o contexto sociopolítico, nos idos anos de 1964, tempo de obscuridade no Brasil, em pleno regime militar, exatamente o oposto acontecia com o processo de formação iniciado no exercício de sua nova função como orientadora educacional na rede de ensino municipal. E, certamente, a experiência adquirida nesse processo ampliou a sua atuação em outras esferas da formação:

Com o curso de pedagogia fui trabalhar na orientação educacional. Na época, no município, havia um forte movimento: tinha uma assessoria à orientação educacional, um peso nas escolas, um grupo que dava apoio e discutia. A Regina Leite Garcia era nossa assessora. Foi um outro momento de guinada na minha vida. Nele, pude desvendar um compromisso mais político com a educação. Na assessoria à orientação educacional tivemos um processo de formação que em muito contribuiu para que ficássemos mais ligadas, estudávamos, e comecei a ver a educação nesse sentido mais amplo e comprometido. Não que antes não fosse comprometido, mas eu não percebia. A orientação e a supervisão educacional tinham um papel contrário, mas foi exatamente com essa experiência que pude perceber como o contexto do país interfere e como não podemos ficar alheios a isso. Foi um grande desafio para mim, apesar de ter me formado no ano do golpe, me tornando professora, era completamente alienada dessa estrutura. Nesse ano, eu não tinha clareza dessa situação e só vim a ter muito tempo depois, com as discussões que fazíamos com o grupo da Secretaria. Foi nesse movimento que fui parar na Associação dos Orientadores Educacionais, na diretoria, e foi um tempo de luta, também interna, numa experiência que nunca tinha vivido. Viajávamos para outros estados, na organização da categoria. Foi uma escola pra mim. Fiquei duas gestões na diretoria e nesse período organizamos um Congresso Nacional de Orientação Educacional. (Maria Luiza, Programa de Educação Juvenil - PEJ/SME/RJ)

Ressaltar a complexidade dos processos de formação nos desafia e motiva a pensar em outros caminhos e possibilidades que considerem as diferentes dimensões racionais, afetivas, epistemológicas, cognitivas, éticas, estéticas, políticas, sociais, todas tecidas na mesma trama que compõe os homens e as mulheres, os educadores e as educadoras. Essas di- 
mensões nos processos de formação dão uma amplitude ao desafio de nossa tarefa, ao mesmo tempo em que exigem estabelecer, a todo momento, relações entre a prática pedagógica e os múltiplos saberes e conhecimentos que a informam, entre o ofício de educar entendido como prática social e sua relação com a sociedade, e os diferentes tempos/espaços da educação, tais como: o cotidiano das práticas educativas, comunitárias, culturais, associativas, as escolas, as ruas, as praças, os espaços públicos, culturais, políticos, os diferentes grupos com os quais interagimos, os entre-lugares que se constituem nos interstícios de diferentes lugares, assim como era a experiência com os Coletivos de Autoformação.

Os horizontes dos processos de formação estão intimamente relacionados aos modos de se perceber a educação e as diferentes formas de aprender. Sobre as formas de aprender, tenho me aproximado de um entendimento de tessitura de conhecimentos em rede, onde os conhecimentos, metaforizados em fios, vão ser ressignificados pelos sujeitos de maneira única e singular a partir de seus interesses, valores, crenças, saberes, vinculando-se à experiência própria de cada um, alargando suas móveis fronteiras pessoais, sociais e culturais delineadas por muitos outros fios e nós. Não mais a metáfora da árvore do conhecimento, presente no paradigma dominante, na qual os saberes são hierarquizados e adquiridos em um processo individual e cumulativo, no qual precisamos galgar degraus paulatinamente até alcançar os frutos raramente disponíveis para todos.

A metáfora da rede fluida no tempo e no espaço exige pensar nas formas de relações entre o local e o global, entre o uno e o diverso, entre cada educador e educadora e seu espaço de ação no que tem de interativo e coletivo. Como bem diz Inês Barbosa de Oliveira (2001):

Pensar, por exemplo, a formação de professores a partir da idéia de tessitura do conhecimento em rede é, em primeiro lugar, investir no saber da experiência e numa pedagogia interativa e dialógica, como um processo investigativo constante que se faz solidariamente com parceiros na pró- pria caminhada. A troca de experiências e de saberes tece/ destece/retece espaços/tempos da formação mútua, nos quais cada professor é chamado a desempenhar, simultaneamente, o papel de formador e de formando. [...] Quando quem faz coletiviza esse fazer, por meio da linguagem do saberfazer, ensina e aprende com seus pares. (p. 71)

Sobre os modos de compreender a educação, posso dizer que a complexa e difícil arte de educar, de produzir e criar sentidos perpassa o campo da formação/autoformação e nos indaga a respeito de sua possibilidade de emancipação, entendendo emancipação no sentido que Boaventura Santos atribui ao termo: como autoconhecimento, condição de escolha, de produção de alternativas cotidianas, de exercício do político nos espaços estruturais, de criação e recriação da vida, dos sonhos que nos movem em direção a algo que ainda não alcançamos.

A perspectiva emancipatória situa-se na tensão entre aquilo que regula e o que se anuncia como emancipatório, pois não basta só escolher o caminho, mas fazê-lo e refazê-lo ao caminhar. Ao movimento de emancipação corresponde outro de limitação, de autodeterminação, e é nessa tensão que ora avançamos, ora retrocedemos. Pensar sobre emancipação é, também, admitir que nada é absolutamente emancipatório, libertador, pois como seres humanos somos, ao mesmo tempo, isto e aquilo, trazemos em nós tanto o angelical como o demoníaco, que, a qualquer momento, podem se revelar tanto nas idéias como nas ações. Assim, uma ação emancipatória é uma possibilidade de produção contínua, num processo que nos exige, permanentemente, uma auto-reflexão.

A educação pode ser um espaço de integração e criação de novas formas de convívio e de sociabilidade, um vasto campo de possibilidades de experiências, aprendizados, confrontos, confiança, afetos e sentidos, não só em relação ao que sabemos, acumulado e circulante, mas do que podemos vir a ser e a saber, e do que precisamos exercitar para que consolidemos nossa autonomia. A educação, assim, pode ser um lugar das interrogações sobre o estabelecido, de ampliação dos sentidos de ser e estar no mundo. 
Ter como utopia que os processos de formação podem ser espaços privilegiados por favorecerem o encontro entre as pessoas, podendo contribuir tanto no desenvolvimento de relações que estabeleçam a igualdade, quanto na criação de condições de respeito às diferenças, ou numa produção coletiva que propicie uma outra qualidade de existência na qual o valor maior seja a vida, em sua plenitude e dignidade, é o que nos impulsiona nessa busca, provavelmente inesgotável.

São os passos desse caminhar que desbravam as possibilidades, que nos fazem avançar no próprio caminhar e no modo de abertura de fronteiras, marcando com as pegadas cotidianas as alternâncias que produzimos para melhorar as condições do futuro. É o que nos faz interrogar com afinco aquilo que nos parece óbvio, que foi sendo naturalizado, normalizado $\mathrm{e}$, muitas vezes, aceito com aparente passividade.

\section{Quinto movimento: indícios metodológicos para a formação/autoformação}

As práticas pedagógicas dos educadores devem ser consideradas em sua complexidade, pois referemse às diferentes redes de formação em que cada um está inserido. Assim, as histórias de vida, os percursos profissionais, os sentidos e significados criados e recriados ao longo de uma trajetória são fundamentais e constitutivos daquilo que se é, mesmo quando marcados por preconceitos, dificuldades e conservadorismo. E tudo isso deve ser incorporado aos processos de formação que, fundamentalmente, devem confrontar e ampliar essas redes com outras contribuições.

Se considerarmos que é necessário uma nova articulação entre cidadania, emancipação e subjetividade (Santos, 1999), a essa necessidade vêm se somar as histórias de vida enquanto possibilidades de articulação das subjetividades do sujeito com as dimensões coletivas nas quais estamos inseridos, de forma que essas articulações possam nos fortalecer no enfrentamento das condições adversas, favorecendo um exercício emancipador nas práticas coletivas, restabelecendo as conexões entre sujeito e história.
Na experiência dos Coletivos de Autoformação, esta articulação entre o sujeito, suas singularidades e a tessitura de um fazer coletivo esteve presente o tempo todo, tal como bem ilustra esse trecho da história de Florine, educadora integrante do Coletivo do Rio de Janeiro:

A minha formação era marxista e cristã. Hoje sei que são duas coisas, mas bem iguais. Na época, eu não achava. Tinha altos conflitos, vivia uma contradição, porque no marxismo você não acredita em Deus, e o Oscar me apresentava a teoria marxista, que se encaixava em tudo, era uma ferramenta perfeitamente lógica para você explicar o mundo, as desigualdades sociais. E ainda acho, mesmo sendo anarquista, que o marxismo ainda é uma ferramenta de análise da realidade, não é para jogar no lixo, não.

O que me mobilizou no ambiente da cultura e da educação popular tinha a ver com a minha formação cristã. Apesar de ter estudado em colégio de freiras, lembro que naquela época tinha João XXIII, que era uma renovação da Igreja. Lembro de duas professoras, uma a madre Angélica, que era psicóloga e orientadora da escola, e tinha uma visão assim mais aberta das coisas, e a madre Vilma, que era assim uma precursora da Igreja progressista, mais comprometida com o social, da linha de Frei Beto. E isso se juntou com o marxismo, que eu descobria através do Oscar, que eu estava namorando. Fiquei fascinada, porque o Oscar naquele tempo foi uma revolução pra mim. Ele fazia História no IFCS, no Largo de São Francisco, pertencia a um grupo de esquerda e tinham muitas discussões, apesar do momento em que o país vivia, em plena ditadura. Íamos nas sessões da meia-noite, no Cinema 1, e depois ficávamos horas discutindo no Beco da Fome, em Copacabana. Era uma geração muito idealista, quase romântica, a nossa. E tive muita sorte de pertencer a esse grupo, pois foi aí que reafirmei meu compromisso com o social. Tinha algumas pessoas desse grupo que me olhavam com uma certa reserva: eu vinha do Leblon, lugar de burguesia, filha de militar, mas eu não tinha culpa de morar lá. Esse foi um momento bastante rico na minha formação ideológica. Muita discussão, muito medo também. De vez em quando, eu me lembro de uma colega dizendo "Ah, o Roberto sumiu". E as pessoas sumiam assim. Era difícil. 
É nesse contexto que se dá minha primeira experiência profissional, e percebi que era isso que eu queria fazer na vida: queria ser professora.

A escolha de trabalhar com histórias de vida é para melhor entender que o que fazemos e o como fazemos estão relacionados a processos mais amplos e complexos de nossa vivência e de nossa inserção no mundo, do que apenas àqueles que se referem estritamente à formação específica e/ou profissional. Assim, os modos de ser e de fazer expressos em várias dimensões de nossa existência, os caminhos pelos quais fomos nos tornando educadores, a relação que estabelecemos com os alunos e outros parceiros do mesmo ofício são importantes fios que se entrelaçam no entendimento da qualidade da relação que procuramos no ato de educar. A intenção é perceber a complexidade que nos constitui, sem mais nos dividir em instâncias fragmentadas, dicotomizando o que somos do que fazemos, mas tentando nos perceber como sujeitos "inteiros", exercendo uma prática educativa que se dá na confluência de valores, saberes, experiências, conhecimentos, crenças e atitudes constantemente negociados na vivência coletiva.

Uma turma de amigos ligados à Pastoral da Juventude criou o projeto de alfabetização para adultos, o "Educar para a vida" e me convidaram para participar como educadora. O projeto já existia há um ano e atuei nele durante cinco anos. Quando entrei, não era remunerado e só acontecia de noite. No ano seguinte, vimos a possibilidade de montar turmas à tarde com as senhoras que não podiam estudar à noite. Apesar de algum preparo, de ter técnicas para estar dentro de sala, a vivência e a experiência com os grupos eram totalmente diferentes do que tinha aprendido. Me sentia muito mais próxima, e ali me identifiquei. No início, as aulas funcionavam no salão paroquial, depois passamos para uma sala no pátio da igreja, ainda precária, embora melhor que o salão, que era de uso coletivo. O projeto nos aproximou muito das pessoas de Imbariê. Era muito bom conversar com os adolescentes, orientá-los, ajudálos. Tivemos problemas com a questão do funk, que naquela época estava um pouco pesada, com a questão do tráfico, adolescentes sendo ameaçados ou mesmo mortos, adolescentes engravidando muito novinhas. E nessa relação percebia o quanto podíamos ser agentes transformadores, quando orientávamos e conversávamos sobre essas questões, mais do que quando passávamos os conteúdos do reforço escolar. A relação com as senhoras, com os adultos, foi talvez a mais forte. Criamos muitos laços fortes, de estar trocando idéias, conversando, aprendendo também com elas. Aquilo era diferente para mim, e eu não identificava essa possibilidade na rede pública. Trabalharia com crianças; que as minhas professoras no normal diziam que eram cheias de problemas, e nos amedrontavam no sentido que não poderíamos estar fazendo alguma coisa de bom. Agora eu tenho uma outra visão. Esta experiência no "Educar para a vida" me mostrou que posso estar fazendo alguma coisa de bom mesmo nas salas da rede pública. Para mim, esta que é a diferença, de ser uma pessoa que troca, que recebe, que está sendo útil. Se eu tivesse ido direto para a rede, talvez eu não tivesse esta visão. O projeto me ensinou a ser uma educadora e me deu ânimo para entrar na rede.

Atualmente estou trabalhando só no CADTS - Centro de Aprendizagem Desenvolvimento Técnico Social no bairro de São Mateus, em São João de Meriti. Essa experiência começou em 1998, quando fui convidada por Sueli, que mora aqui em Imbariê e trabalha há muitos anos no CADTS. Fui convidada para trabalhar com jovens e adultos em uma proposta de educação mais voltada para a área técnica. O CADTS é uma escola de ensino profissionalizante. Oferece quatro cursos: mecânica-eletricista, instalador, eletrônica e informática. Fui trabalhar com matemática, porque estes cursos exigem conhecimentos nessa área. Trabalhei durante cinco meses, saí, retornei em 1999, e atualmente faço parte da equipe de instrutores. Além do trabalho direto, tenho tido a oportunidade de participar de encontros, discussões com outras escolas, tenho viajado para conhecer outras escolas de ensino profissionalizante, e isso tudo tem me fortalecido muito.

Esse trecho da história de Andréa, educadora integrante do Coletivo do Rio de Janeiro, ilustra magistralmente o que apontam as pesquisas de Goodson (1992): vida e formação caminham juntas. Não há mais sentido em separar ou deixar do lado de fora 
aquilo que se é no exercício da profissão; somos o que somos nos diferentes espaços que percorremos, apesar de nossas múltiplas identidades. Isso não significa dizer que estamos prontos e acabados, pois essa é uma impossibilidade humana, mas o que nos modifica no âmbito profissional também nos modifica no nosso jeito de ser, e vice-versa. O eu-pessoal está intimamente relacionado ao eu-profissional; juntos formam uma só pessoa, o que implica dizer que se queremos avançar na questão da formação de educadores devemos trabalhar com a polissemia, a polifonia e com o que essa multiplicidade traz de possibilidade de confronto, mas também de diálogo a partir desse encontro. Esse é um importante indício a ser considerado nos processos de formação.

Outro indício extraído da experiência dos Coletivos de Autoformação foi o de ter tido a prática como o guião condutor das ações, acreditando que aprendemos com o que fazemos, que os saberes são oriundos daquilo que usamos. Ao tomarmos a prática como matéria-prima para a reflexão e o aprofundamento, temos mais condições de articulá-la com outras contribuições teóricas, em um movimento constante e dinâmico prática/teoria/prática, o qual possibilita um permanente refazimento de nossas ações, ao mesmo tempo em que nos alimenta de perguntas cada vez maiores.

$\mathrm{O}$ que mais nos interessava eram as pessoas e os seus fazeres pedagógicos, os múltiplos saberes presentes em sua atuação, a forma como interagiam e se expressavam na criação e recriação de outros conhecimentos, atribuindo outros significados à dinâmica dos acontecimentos pedagógicos e, sobretudo, como nos apropriávamos de um lugar no exercício desse fazer.

Nessa experiência estes saberes se faziam presentes nas atitudes, valores, escolhas temáticas, o que nos conduziu sucessivas vezes a uma negociação sobre o que pudesse ser mais enriquecedor para o conjunto, favorecendo um exercício democrático vigoroso e dinâmico que interferia na mudança de rumos durante o processo de autoformação.

Os Coletivos, tanto o do Rio de Janeiro quanto o de Pernambuco, envolviam poucos educadores; cada grupo tinha uma média de 20 a 25 pessoas, mas a idéia de tomar em suas mãos a tarefa de conduzir a própria formação, de maneira sistemática e autônoma, ultrapassava a pequena fronteira desse espaço de mediação para se colocar como um desafio e necessidade para muitos outros professores e educadores, sobretudo os vinculados às experiências governamentais que lidam no seu dia-a-dia com um grande contingente de alunos e sequer têm tempo de respirar entre as muitas atribuições do seu fazer.

Tenho a expectativa de que esse Coletivo não seja só o seminário, mas que produza uma discussão sobre formação e materiais, pois existe uma demanda de produção nessa área que se volte tanto para a sala de aula quanto nos possibilite discutir a formação em lugares mais amplos. (Lourdinha, 1994, Rio de Janeiro)

Outro indício está no fato de ter sido uma prática vivenciada entre educadores de diferentes procedências, com diferentes trajetórias de formação e histórias de vida, prática singular e nomeada de autoformação, pois partia do desejo de adesão de cada educador de se vincular àquele espaço refletindo de maneira contínua sobre questões provenientes de seu cotidiano educativo, dispostos a pensar tanto criticamente quanto criativamente sobre os seus fazeres, tentando, nesse esforço, construir uma jangada em pleno mar.

Assim, a reflexão sobre essa experiência traz um outro entendimento da formação que, em vez de moldar, possa mudar, desde que os sujeitos mais interessados se sintam concernidos a participar dessa mudança que é utopicamente mais modesta. Se não é possível mudarmos o conjunto da sociedade, talvez seja possível mudar além de nós mesmos, o que não é pouca coisa, os espaços nos quais atuamos resgatando algumas unidades perdidas entre o que se é e o que se faz. Entre a ação, participação, reflexão e a indissociabilidade da história de vida e do percurso profissional, restaurando conexões entre os diferentes saberes práticos e teóricos, valores, desejos, crenças, atitudes etc.

Se a proposta deste texto foi a de refletir sobre processos de formação/autoformação, percorrendo a experiência dos Coletivos de Autoformação, esse 
percurso possibilitou também mapear indícios de caminhos que podem trazer contribuições às práticas de formação/autoformação, desde que, como diz o sábio chinês Lu Xum:

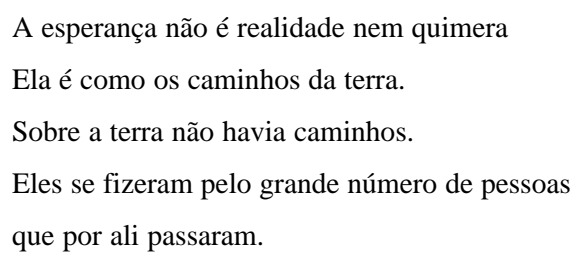

CLEIDE FIGUEIREDO LEITÃO, mestre em educação pela Universidade do Estado do Rio de Janeiro (UERJ), é atualmente professora substituta na mesma universidade, pesquisadora e educadora do SAPÉ - Serviços de Apoio à Pesquisa em Educação, e supervisora pedagógica do Curso de Formação Pedagógica em Educação Profissional na Área da Saúde: Enfermagem, da Escola Nacional de Saúde Pública, da Fundação Nacional de Saúde Oswaldo Cruz (Fiocruz). Últimos trabalhos publicados: Os outros também somos nós (A página da educação, Coimbra, Portugal, p. 19, julho 2003); Cartografia de imagens de práticas solidárias (CDROM do II Seminário Internacional As redes de conhecimento e a tecnologia: imagem e cidadania, 24 a 27 de junho de 2003, UERJ/ ANPEd); Itinerários e processos de autoformação. In: OLIVEIRA, Inês Barbosa de, PAIVA, Jane (orgs.). Educação de jovens e adultos (Rio de Janeiro: DP\&A, 2004, p. 143-158, Coleção “O sentido da escola").

\section{Referências bibliográficas}

ALVES, Nilda, (1998). Trajetórias e redes na formação de professores. Rio de Janeiro: DP\&A.

, (2001). Decifrando o pergaminho: o cotidiano das escolas nas lógicas das redes cotidianas. In: ALVES, N., OLIVEIRA, I. B. de (orgs.). Pesquisa no/do cotidiano das escolas: sobre redes de saberes. Rio de Janeiro: DP\&A, p. 13-38.
ALVES, Rubem, (1993). Conversas com quem gosta de ensinar. $28^{\mathrm{a}}$ ed. São Paulo: Cortez.

BEZERRA, Aída, (1995). Formação/autoformação: uma tentativa de organizar algumas idéias sobre o tema. Rio de Janeiro: SAPÉ. Documento de circulação interna.

BEZERRA, Aída, RIOS, Rute, (1995). La negociación: una relación pedagógica posible. In: Cultura y política en educación popular: principios, pragmatismo y negociación. Haya/Holanda: CESO.

BHABHA, Homi K., (2001). O local da cultura. Belo Horizonte: Editora da UFMG.

CASTORIADIS, Cornelius, (1987). Epilegômenos a uma teoria da alma que se pode apresentar como ciência. In: . . Encruzilhadas do labirinto I. Rio de Janeiro: Paz e Terra, p. 31-68.

CERTEAU, Michel de, (2000). A invenção do cotidiano: artes de fazer. Petrópolis: Vozes.

GOODSON, Ivor F., (1992). Dar voz ao professor: as histórias de vida dos professores e o seu desenvolvimento profissional. In: NÓVOA, A. (org.). Vidas de professores. Porto: Porto Editora, p. 63-78.

NÓVOA, Antônio, (1995). Formação de professores e formação docente. In: NÓVOA, A. (org.). Os professores e a sua formação. Lisboa: Publicações Dom Quixote, p. 13-33.

OLIVEIRA, Inês Barbosa de, (2001). Certeau e as artes de fazer: as noções de uso, tática e trajetória na pesquisa em educação. In: OLIVEIRA, I. B. de, ALVES, N. (orgs.). Pesquisa do/no cotidiano das escolas sobre redes de saberes. Rio de Janeiro: DP\&A, p. 39-68.

SANTOS, Boaventura de Sousa, (1999). A construção multicultural da igualdade e da diferença. Coimbra: Centro de Estudos Sociais (Série Oficina do CES n ${ }^{\circ}$ 135). , (2000). A crítica da razão indolente contra o desperdício da experiência. São Paulo: Cortez.

Recebido em outubro de 2003 Aprovado em fevereiro de 2004 


\section{Resumos/Abstracts}

José Carlos Libâneo

\section{A didática e a aprendizagem do pensar e do aprender: a Teoria Histórico-cultural da Atividade e a contribuição de Vasili Davydov} Apresenta algumas contribuições teóricas da pesquisa sobre a psicologia histórico-cultural e a Teoria Históricocultural da Atividade para o pensamento didático. Inicialmente, são sugeridos caminhos para linhas de investigação em didática em relação aos processos de formação de conceitos e desenvolvimento do pensamento. Em seguida, é apresentado um breve histórico da Teoria Histórico-cultural da Atividade e de conceitos básicos a partir de Vygotsky e alguns de seus seguidores. Finalmente, são apresentadas idéias de Vasili Davydov sobre as relações entre ensino e desenvolvimento mental e as bases do ensino desenvolvimental voltado para a formação do pensamento teórico.

Palavras-chave: didática; Vasili Davydov; Teoria Histórico-cultural da Atividade

The didactics and learning of thinking and learning: the Historicalcultural Theory of Activity and the contribution of Vasili Davydov

The article presents some theoretical contributions on research on Historical-cultural psychology and Historical-cultural Theory of Activity for pedagogical thinking. Initially, it suggests paths for lines of investigation in didactics with relation to processes of formation of concepts and development of thinking. It then presents a brief history of the Historical-cultural Theory of Activity and of fundamental concepts based on Vygotsky and some of his followers. Finally, it presents Vasili Davydov's ideas on the relation between teaching and mental development and the bases of developmental teaching directed to the formation of theoretical thinking. Key-words: didactics; Vasili Davydov; Historical-cultural Theory of Activity

Cleide Figueiredo Leitão

Buscando caminhos nos processos de formação/autoformação

A partir da experiência dos Coletivos de Autoformação realizados pela organozação Serviços de Apoio à Pesquisa em Educação (SAPÉ), o texto propõe uma reflexão sobre questões relacionadas à formação de professores de jovens e adultos, considerando as expressões das culturas locais, as singularidades, os saberes cotidianos que são produzidos nas práticas educativas, a diversidade dos sujeitos envolvidos, as histórias de vida e as relações entre o que se é e o que se faz, a articulação possível a partir das diferenças e a produção que pode ser feita no interstício entre diferentes lugares. Sugere como indícios às propostas de formação o incentivo a formas de organização dos professores em cada unidade educativa em um processo de autoformação partilhada, que possibilite a reflexão sobre as suas práticas; e a criação de espaços de trocas e convivências nos quais se possa exercitar a crítica, a criatividade e o aprofundamento das relações entre prática/teoria/prática, favorecendo um exercício autônomo e sistemático dos seus fazeres, saberes, poderes.

Palavras-chave: educação de jovens e adultos; formação de professores; entre-lugares

Searching for paths in processes of formation and self-formation The objective of this article is to reflect upon questions related to the formation of teachers for adult and youth education based on the experience of the Collectives of Self-formation organised by the Service of Support for Research in Education (SAPE), taking into consideration expressions of the local culture, its singularities and the different kinds of daily knowledge that are produced in educational practices, as well as the variety of individuals involved, their life histories and the relations between what we are and what we do and including the possible articulation based on differences and what can be produced in the interstice between different places. It suggests as possible proposals for formation: ways of organising teachers in each educational unit in a shared process of 
self-formation, which allow them to

reflect on their practice, the creation of spaces for exchange and conviviality in which individuals can exercise criticality, creativity and a strengthening of the relations between practiceltheory/practice, promoting the autonomous and systematic exercise of their actions, knowledge and powers.

Key-words: adult and youth education; formation of teachers; between-places

Lúcia Velloso Maurício

\section{Literatura e representações da} escola pública de horário integral $\mathrm{O}$ artigo apresenta o confronto entre $\mathrm{o}$ que se depreende da literatura produzida entre 1983 e 2001 sobre a escola pública de horário integral e a representação social que usuários e trabalhadores construíram sobre este tema. Após análise temática da literatura pertinente, realizou-se pesquisa de campo em quatro Centros Integrados de Educação Pública (CIEP) de $1^{\mathrm{a}}$ a $4^{\mathrm{a}}$ série, localizados em bairros populares, para identificar a representação social construída por alunos, pais, professores e funcionários. Nem todas as questões colocadas pela literatura foram contempladas no campo. Entretanto, ficou evidenciada a existência de duas óticas distintas a respeito da função social desta escola e dos fatores mobilizadores para sua demanda. De um lado, a representação dos professores, centrada na necessidade do aluno como justificativa para essa escola, assemelha-se aos argumentos encontrados na literatura. De outro lado, a representação dos pais e alunos, centrada na satisfação, contempla as idéias de lazer, futuro e educação.

Palavras-chave: escola pública de horário integral; representação social; necessidade $x$ satisfação

\section{Literature and representations} concerning full-time public schooling This article compares the literature produced between 1983-2001 on full- time public schooling and the social representation that users and workers formed about it. After analysing the main themes of the relevant literature, four Integrated Centres of Public Education (CIEP) were selected, in working-class districts, in order to identify the social representations created by their students, parents, teachers and administrative staff.

Although some of the questions raised by the literature could not be verified, the research indicated the existence of two different social representations about the full-time public school and the demand for it. One of them was the teachers'view, based on the needs of children to justify the maintenance of these schools, which was similar to the arguments found in the literature. The other was the social representation of parents and school children and was formed around the notion of satisfaction, contemplating the ideas of leisure, future and education.

Key-words: full-time public school; social representation; needs $\mathrm{x}$ satisfaction

Eurize Caldas Pessanha, Maria Emília Borges Daniel e Maria Adélia Menegazzo

Da história das disciplinas escolares à história da cultura escolar: uma trajetória de pesquisa

Este texto reflete sobre a trajetória que o grupo de pesquisa Professores e Disciplinas Escolares da Universidade Federal de Mato Grosso do Sul vem percorrendo e sobre como, partindo de pesquisas sobre a história das disciplinas escolares, o grupo chegou ao estudo da história da cultura escolar. Para essa reflexão, são analisados os pressupostos do campo de investigação conhecido como "história das disciplinas escolares", conforme Chervel, e os conceitos de cultura e cultura escolar, de acordo com Wiliams, Forquin, Julia, Faria Filho, Viñao-Frago e Escolano. O artigo argumenta que a investigação sobre a cultura escolar de uma determinada escola pode conduzir à reconstituição da história da cultura escolar de uma cidade.

Palavras-chave: cultura escolar; currículo; disciplinas escolares

From the history of school subjects to the history of school culture: a research trajectory

This text is a reflection on the trajectory that a research group on "Teachers and School Subjects", from the Federal University of Mato Grosso do Sul, has been pursuing and on how it arrived at the study of history of school culture, starting from research into the history of school subjects. For this reflection we analyse presuppositions from the field of investigation known as "history of school subjects", according to Chervel, and concepts of culture and school culture, as posited by Williams, Forquin, Julia, Faria Filho, ViñaoFrago and Escolano. We argue that research into the school culture of a determined school can lead to the reconstitution of the history of school culture in a specific city.

Key-words: school culture;

curriculum; school subjects

Antonio Miguel e outros

A educação matemática: breve histórico, ações implementadas e questões sobre sua disciplinarização Este trabalho foi elaborado em tópicos autônomos para discutir a configuração da educação matemática como área de pesquisa e, num panorama histórico, expõe e analisa como têm sido implementados, efetivamente, esforços para sua consolidação no Brasil. A partir da apresentação de alguns elementos relativos à emergência e à organização da pesquisa em educação matemática no panorama internacional (D'Ambrósio), ele passa a esboçar as motivações e estran- 